\title{
School-Based Interventions for Promotion of Healthy Lifestyle and Behavior: How Effective Are They?
}

\author{
Rajni Sharma ${ }^{1} \mathbb{0}$
}

Received: 21 December 2021 / Accepted: 27 December 2021/Published online: 15 January 2022

(c) Dr. K C Chaudhuri Foundation 2022

Noncommunicable diseases (NCD) such as obesity, diabetes mellitus, hypertension, and cardiovascular disease are emerging as the leading cause of morbidity and mortality in adults. These diseases are related to lifestyle and faulty habits which often develop in childhood and adolescence. Childhood obesity (a harbinger of metabolic syndrome and NCD) has reached epidemic proportions in urban and rural areas with $19.3 \%$ of Indian children being reported as overweight/ obese [1]. Children spend majority of their time in school; hence, school-based interventions to inculcate a healthy lifestyle seem logical. However, the results of such studies in various parts of the world have had mixed results depending on the setting, age of children, duration, method used and intensity of the intervention [2]. The studies are also highly heterogeneous in the outcomes assessed, which range from knowledge, change in dietary practices, accelerometerassessed physical and sedentary activity, anthropometric data [change in body mass index (BMI), or proportion of children overweight/obese], or metabolic parameters (blood pressure, serum lipids). Most of the lifestyle measures focus on the '5-2-1-0' obesity prevention guideline for children ( $\geq 5$ servings of fruits and vegetables, $\leq 2 \mathrm{~h}$ of screen time, $\geq 1 \mathrm{~h}$ of physical activity, and 0 sugar-sweetened beverages) recommended by the American and Indian Academies of Pediatrics.

In this issue of the Journal, Mahajan et al. report the results of a school-based intervention on promotion of healthy lifestyle and behavior among adolescents in 12 private and government schools in Shimla [3]. It was a large cluster-randomized, controlled trial targeting nutrition, physical activity, and antitobacco and alcohol consumption education intervention which was delivered by the school

Rajni Sharma

drrajnisharma@yahoo.com

1 Division of Pediatric Endocrinology, Department of Pediatrics, All India Institute of Medical Sciences, Room no.3058, Teaching Block, New Delhi 110029, India teachers to secondary school students over a period of $1 \mathrm{y}$. However, the results showed no significant improvement in the nutrition knowledge or health behavior with the intervention. There was no difference in the secondary outcomes of anthropometric or biochemical parameters either. On a positive note, there was a significant decrease in consumption of junk food. In this study, more than $90 \%$ adolescents were already physically active at baseline, as they walked long distances to school in hilly terrains and the intervention did not affect the activity level.

How does this study compare to other studies from India and abroad? If we consider the age of children, primary school interventions are generally less effective showing marginal or no benefit of intensive lifestyle education and physical activity promotion among children and their parents on improving dietary practices, physical activity, or changing BMI [4]. The lesser impact on primary school children may be, in part, due to larger environmental determinants or lack of motivation for change among parents of younger children [4]. On the other hand, healthy lifestyle interventions may be more effective in adolescent age groups, who are in a period of transition and need of guidance [5-7]. Shah et al. found baseline knowledge regarding health, and nutrition was severely lacking in urban Indian school children with significant improvements after intensive education sessions [5]. Of note, these education sessions were conducted by researchers and not teachers, in contrast to the study by Mahajan et al. Due to academic pressures of secondary school, teachers may not be the ideal agent to deliver lifestyle education unless embedded in the curriculum [5-7]. In another study from an urban area in Pune, Bhave et al. reported significant improvements in physical fitness with a 5-y school-based education program focusing on healthy nutrition and promotion of physical activity, though it did not decrease BMI or the prevalence of overweight/obesity [8]. School-based interventions were found to be more effective if accompanied by a simultaneous change in school policy (ban on junk food/packaged food in canteen 
and availability of more healthy alternatives, compulsory sports, and games periods) and involvement of families and peers [5-8]. However, these interventions may still not be sufficient in children who are already overweight or obese and require more intensive clinical and family-based programs $[4,7,8]$.

What are the implications of the study? The effectiveness of school-based intervention to promote healthy lifestyle would depend on the settings (urban vs. rural, facilities for physical activity arenas, transport), school policy, and parental lifestyle. A meaningful impact on health behaviors of the population calls for bigger measures at the government (example: creation of open spaces and playgrounds, promotion of community sports, etc.) and legislative level [example: taxes on junk food and sale of high fat sugar and salt (HFSS) foods]. Also, the overriding influence of media should be kept in mind while designing a program for health promotion and NCD prevention in children.

\section{Declarations}

Conflict of Interest None.

\section{References}

1. Ranjani H, Mehreen TS, Pradeepa R, et al. Epidemiology of childhood overweight \& obesity in India: a systematic review. Indian J Med Res. 2016;143:160-74.
2. Waters E, de Silva-Sanigorski A, Hall BJ, et al. Interventions for preventing obesity in children. Cochrane Database Syst Rev. 2011. https://doi.org/10.1002/14651858.CD001871.

3. Mahajan A, Negi PC, Gandhi S, Sharma D, Grover N. Impact of school-based health behavioral intervention on awareness, practice pattern of healthy lifestyle, and cardiometabolic risk factors among school children of Shimla: a cluster-randomized, intervention study. Indian J Pediatr. 2021. https://doi.org/10.1007/ s12098-021-03786-6.

4. Lloyd J, Creanor S, Logan S, et al. Effectiveness of the healthy lifestyles programme (HeLP) to prevent obesity in UK primaryschool children: a cluster randomised controlled trial. Lancet Child Adolesc Health. 2018;2:35-45.

5. Shah P, Misra A, Gupta N, et al. Improvement in nutrition-related knowledge and behaviour of urban Asian Indian school children: findings from the "Medical education for children/adolescents for realistic prevention of obesity and diabetes and for healthy aGeing" ( MARG) intervention study. Br J Nutr. 2010;104:427-36.

6. Saraf DS, Gupta SK, Pandav CS, et al. Effectiveness of a school based intervention for prevention of non-communicable diseases in middle school children of rural North India: a randomized controlled trial. Indian J Pediatr. 2015;82:354-62.

7. Singhal N, Misra A, Shah P, Gulati S. Effects of controlled schoolbased multi-component model of nutrition and lifestyle interventions on behavior modification, anthropometry and metabolic risk profile of urban Asian Indian adolescents in North India. Eur J Clin Nutr. 2010;64:364-73.

8. Bhave S, Pandit A, Yeravdekar R, et al. Effectiveness of a 5-year school-based intervention programme to reduce adiposity and improve fitness and lifestyle in Indian children; the SYM-KEM study. Arch Dis Child. 2016;101:33-41.

Publisher's Note Springer Nature remains neutral with regard to jurisdictional claims in published maps and institutional affiliations. 